\title{
Reapropriação de arquivo e imantação de afeto
}

\section{CARLOS ADRIANO}

\section{Resumo}

Sob a forma de testemunho pessoal, o artigo pensa a pauta do arquivo e de seu natural e consequente corolário (o da apropriação deste arquivo) como uma das mais pertinentes hoje. Como operar de maneira crítica e criativa perante um manancial aparentemente inesgotável de materiais? Como saber encontrar (o grande achado da apropriação) os materiais que se procura? Como organizá-los de modo Arquivo, cinema, reapropriação inteligível e sensível? 


\title{
Found footage and magnetization of affection
}

\section{CARLOS ADRIANO}

\begin{abstract}
Under the form of a personal testimony, this article thinks the agenda of the archive and its natural and consequent corollary (the appropriation of the archive), as one of the most relevant today. How is it possible to operate critically and creatively at an enormous amount of material? How to know the way to find (the great find of found footage) the materials searched? How to organize them into an intelligibly and sensitive form?
\end{abstract}

Keywords:

Archive, film, found footage 


\section{Reapropriación del archivo e imantación del afecto}

\section{CARLOS ADRIANO}

\section{Resumen}

Bajo la forma de testimonio personal, el artículo piensa la pauta del archivo y de su natural y consecuente corolario (el de la apropiación de este archivo) como una de las más pertinentes hoy. ¿Cómo operar de manera crítica y creativa frente a un manantial aparentemente inagotable de materiales? ¿Cómo saber encontrar (el gran hallado de la apropiación) los materiales que se procura? ¿Cómo organizarlos de modo inteligible y sensible? 
$\mathbf{E}_{\text {ste artigo provém de um relato assumidamente pessoal, por- }}$ que quis, como convidado da conferência Arquivos, Memórias, Afetos, dar testemunho de minha trajetória e experiência. Tentarei manter e me ater ao protocolo acadêmico, embora minha condição bipolar - de artista e de pesquisador - apronte e aponte derivas pelo caminho. Assim não me furtarei ao chamado do coté poeta como (qu)id misterioso, sub superego. Seguirei uma cronologia, mas sem ter com alvo qualquer teleologia.

Desde meu terceiro filme (iniciado em 1994 e finalizado em 1997), tenho me dedicado, de forma programática embora involuntária, ao cinema de reapropriação de arquivo, o chamado found footage, aquele "gênero" ou procedimento de produção audiovisual que se apropria, recicla, reedita e ressignifica imagens alheias. $\mathrm{O}$ found footage poderia ser traduzido como "metragem [de filme] encontrada". Mas como dar conta e canto ao que expressão guarda e segreda? O encanto do encontro. A graça do assombro.

Atualmente, o mundo parece ter se convertido num imenso banco de dados de imagens e de sons. A proliferação acelerada e desenfreada das tecnologias digitais veio a permitir inéditas e insuspeitadas (até então, há pouco mais de duas décadas) formas de armazenamento, indexação, produção, reprodução e difusão de imagens e de sons. $\mathrm{O}$ mundo como arquivo tornou-se uma baliza não só para a criação de obras artísticas, mas também para a reflexão analítica sobre fenômenos e produtos audiovisuais.

Não só a institucionalização da arte é questão atual. Com a disponibilidade de novas e inúmeras ferramentas de catalogação, é o próprio mundo que se disponibiliza (mesmo que às vezes não se coloque clara e facilmente à disposição) para ser institucionalizado (e catalogado, e domesticado). Assim, o escrutínio crítico de tal situação afigura-se como um chamado instigante para a atividade acadêmica: tratar do mundo "impuro" com seus parâmetros de rigor e método. 
Portanto, a pauta do arquivo, e de seu natural e consequente corolário (o da apropriação e reutilização deste arquivo), é uma das mais urgentes e pertinentes de hoje. Como operar de maneira crítica e criativa perante um manancial aparentemente inesgotável de materiais? Como saber encontrar (o grande achado do found footage) os materiais que se procura? Como organizar estes materiais de modo inteligível e sensível? ${ }^{1}$

Mallarmé estimava que o mundo existia para acabar em livro, e não à toa seu grande projeto (inacabado) de Livro, a partir do ousado lance de dados, buscava uma síntese do mundo sob(re) a forma da arte. Em outra vertente, mais irônica, mas não menos radical e ambiciosa, Flaubert pretendia o mesmo, e também redimir às avessas o mundo, com o seu Tolicionário ou dicionário de ideias feitas. Em outro registro, fabuloso e fabular, Borges, com seus livros de areias e jardins que se bifurcam, também pretendeu encapsular o mundo numa clepsidra de maravilhas transtemporais.

Caleidoscópio em movimento, mosaico audiovisual. O cinema, a arte-chave que não apenas retratou as mudanças radicais do século 20, mas também moldou o imaginário deste decisivo século e do não menos decisivo e formador século 19, tornou-se a memória do mundo. E se tornou fonte e referência para os estudos da história e para as criações artísticas.

Numa linhagem estrutural do found footage, em trajeto de constância (e, espero, de consistência), detecto uma tônica dominante: a reapropriação de raros, desconhecidos ou esquecidos fragmentos cinematográficos da memória cultural brasileira. Na impossibilidade de comentar, no espaço desta conferência, todos os 13 filmes realizados nos últimos 27 anos, passarei por alguns e me deterei em outros.

Meu primeiro filme de reapropriação de arquivo é Remanescências (1994-1997), realizado a partir de 11 fotogramas da suposta primeira filmagem feita no Brasil, registrada em 1897 por Cunha Salles. A imagem, que dura menos de meio segundo de projeção, mostra uma onda batendo num píer.

Não me agrada ver a desqualificação que historiadores impingem à figura de Cunha Salles e seu papel fundador de nosso cinema ${ }^{2}$. Entre inúmeros eventos que poderiam ser catalogados para o ano miragem de 1897, cito o fato de J.J. Thomson ter encontrado a primeira partícula fundamental (o elétron) e S. Mallarmé ter lançado o seu poema crucial Lance de dados.

Por Cunha Salles ser prestidigitador, médico, bicheiro e exibidor, os historiadores não reconhecem ou nem admitem que o fragmento de filme que Salles depositou em 27 de novembro de 1897, no Arquivo Nacional (junto ao processo de patente para 


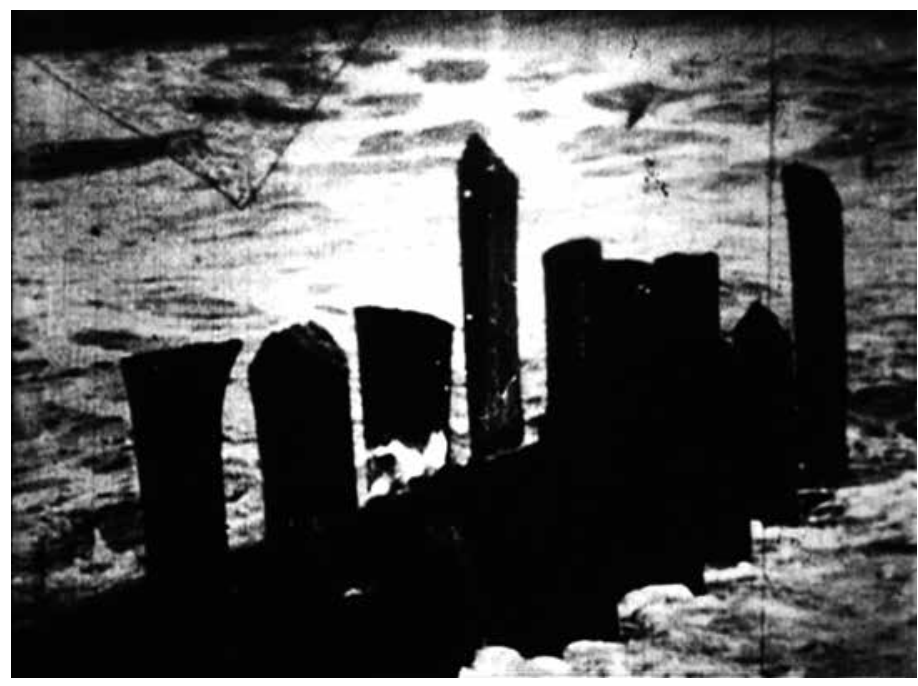

todo um sistema-cinema), possa ter sido filmado por ele, o que o creditaria como autor do primeiro filme nacional.

Se o argumento fosse baseado em exame técnico da película (formato da perfuração, divisão de quadro), eu até poderia achar aceitável uma contestação. Mas, não porque sua veleidade multidisciplinar atestasse falta de seriedade ou de credibilidade, como a comprovar uma suposta condição atávica de eternos condenados macunaímicos.

Ora, prefiro ver que o tal nascimento do cinema brasileiro seja fundado sob a condição de found footage. Se a autoria do filme é questionável, é inconteste a apropriação que Cunha Salles fez deste fragmento de filme eventualmente produzido algures, pois há o registro do pedido de patente em que ele afirma anexar um fragmento de filme e há de fato o filme, do qual chegaram até nós 11 fotogramas (ROSA, 2008).

Cunha Salles até pode ter mentido, e o filme não ter sido mesmo cinematografado por ele - se assim for, eu, de minha parte, adoraria que ele tivesse "roubado" o filme de Marey, $L a$ vague (1891), com o qual guarda impressionante semelhança na composição do píer, dando outra conotação às ondas cuja essência remanesce 3 . Portanto, a hipótese do meta-historiador-artista seria: o primeiro filme nacional não foi filmado e sim reapropriado segundo o código found footage, como arquivo inaugural.

Minha investigação do cinema de reapropriação se dá sob a chave da meta-história de Hollis Frampton (1936-1984) tal como a traduzi para o cinema de reapropriação de arquivo em minha tese de doutorado (ROSA, 2008). Em 1971, Frampton publicou
Figura 1

Fotograma do filme "Remanescências" (Carlos Adriano) 
o ensaio Por uma meta-história do filme: notas e hipóteses de lugar comum (For a metahistory of film: commonplace notes and hypotheses), na revista Artforum (FRAMPTON, 2009).

A meta-história é um artifício ético-estético que permite ao artista continuar compondo seus trabalhos de modo que ainda se justifiquem o seu projeto pessoal e a pertinência do meio em que atua. A partir de uma linhagem (à la Ezra Pound e Jorge Luis Borges), elegem-se parâmetros de formação para um programa poético. As novas obras se articulariam com as obras antigas numa constelação de invenção, um arquivo infinito de imagens e sons destinado a inseminar consistência ressonante ao seu processo de produção.

Segundo Frampton,

[O] meta-historiador do cinema se ocupa com a invenção de uma tradição, isto é, um conjunto coerente e manejável de monumentos discretos, a fim de inseminar consistência ressonante no corpo crescente de sua arte. Tais obras podem não existir, e então é seu dever fazê-las. Ou elas podem já existir, em algum lugar fora do perímetro intencional da arte (por exemplo, na pré-história da arte cinemática, antes de 1943)4. E então ele deve refazê-las (FRAMPTON, 2009, p. 136)5.

A construção da tradição dinâmica de Frampton através da investigação e recontextualização de textos históricos é facilitada tanto pelo trabalho do artista como do arquivista, condensados na figura do meta-historiador. Noël Carroll nos lembra que a meta-história de Framptoné, em primeiro lugar, eantes de tudo, importante pelo fato de que é "artisticamente geradora" (ZRYD, 2015).

Carroll sugere que Frampton desenvolveu a noção de meta-história para reconciliar produtivamente duas abordagens opostas de teoria do cinema e crítica de arte dos anos 6o, 70 e 80 que foram centrais para o pensamento de Frampton: "a abordagem essencialista e a abordagem histórica” (CARROLL, 1986-1987, p. 200).

Carroll sugere que Frampton volta-se para a uma teleologia invertida que faz do artista um meta-historiador ativo:

O metahistoriador do cinema, mesmo que aberto à história do cinema, não vê a história do cinema como convergindo para o presente. A história do cinema de fato é híbrida; não há um destino inscrito nela. Em vez disso, agora, no presente, o metahistoriador dá conta da desordem da história do cinema e almeja certas condições do meio, que lhe parecem representar sua quintessência ( CARROLL ,1986-1987, p. 204). 


\section{O crítico continua:}

(...) na história do cinema propriamente dita (...) tais condições não foram de fato exploradas rigorosa e autoconsciemente. Torna-se tarefa do metahistoriador compensar esta falha, para visualizar a história do cinema como teria sido caso esta fosse rigorosamente autoconsciente, para então reconstruí-la 'axiomaticamente'. $\mathrm{O}$ cineasta metahistoriador imagina como a história do cinema deveria ter sido (de acordo com seus critérios), e então segue adiante para realizá-la (CARROLL, 1986-1987, p. 204).

E ele conclui, entre os interstícios retrospectivos e prospectivos: "Pois a conceituação teórica de Frampton foi planejada para sustentar sua sobrevivência como cineasta - não no sentido de subsistência material, mas como forma de manter a continuação de seu trabalho criativo" (CARROLL, 1986-1987, p. 204).

Antes de me deter em outros filmes, menciono de passagem, apenas para pontuar e demarcar o território em que opero, cinco filmes com material de arquivo sobre os dados esquecidos da cultura brasileira ${ }^{6}$.

Re-missões de Mário de Andrade: a imagem evasiva é o filme do primeiro pós-doutorado, ainda em edição, a partir de 28 segundos e 27 fotogramas de imagem do poeta, filmado [em 9,5mm] por Arthur Pereira, em 1933 [em Santa Isabel].

A voz e o vazio: a vez de Vassourinha (1997-1998) trata do original e obscuro sambista paulistano (1923-1942), que gravou seis discos $78 \mathrm{rpm}$.

Militância (2001-2002), a partir de uma série narrativa de seis lâminas de vidro para lanterna mágica fotografada por Militão Augusto de Azevedo (1837-1905), provavelmente entre 1874 e 1887.

Porviroscópio (2004-2006), a partir do único filme feito por Monteiro Lobato (1882-1948), provavelmente entre 1932 e 1939, com registros domésticos de família e animação desenhada sobre a película, e do som de sua última entrevista à véspera da morte.

Das ruínas a rexistência (2004-2007), a partir dos filmes inacabados de Décio Pignatari (1927-2012), rodados entre 1961 e 1962.

Santoscópio $=$ Dumontagem $(2007-2009)$ é o filme que integra minha tese de doutorado. É um filme na linhagem estrutural do cinema experimental. O cinema estrutural, que foi um tema de meu mestrado, é um rótulo polêmico, lançado em 1969 na revista Film Culture 47 por P. Adams Sitney (ROSA, 2000). Uma definição possível, que tenta dar conta de sua característica, é uma espécie de filme que prioriza os materiais, as propriedades e as estruturas essenciais do cinema, 

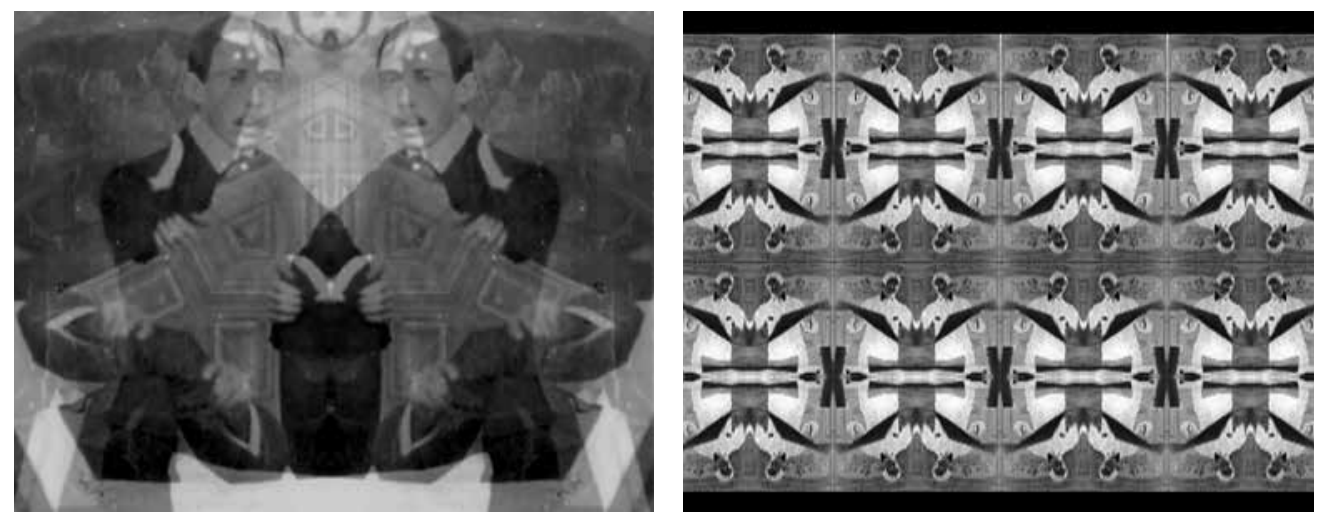

Figura 2 fotograma do filme "Santoscópio = Dumontagem" (Carlos Adriano)

Figura 3 fotograma do filme "Santoscópio = Dumontagem" (Carlos Adriano) numa abordagem materialista em que o cinema se torna mais próximo do pensamento, em que o filme é uma metáfora ou alegoria da consciência.

Santoscópio = Dumontagem recria o mundo do "cinema de atrações", conceito de Tom Gunning e André Gaudreault (GUNNING, 1995; STRAUVEN, 2006), informado pela "nova história do cinema", que, a partir do Congresso da FIAF em Brighton (1978), avaliou o "cinema dos primeiros tempos" ou "cinema das origens" (early cinema) em outros termos, não só por textos (filmes), mas por contextos (documentos de exibição) (ROSA, 2008). Sob a chave da "estética do espanto" (GUNNING, 1995), o "cinema de atrações" é um cinema de relação direta com o espectador, que o interpela sem o recurso da absorção narrativa ou da ilusão diegética. Seu tr(i)unfo está na potência que envolve seu ato básico: mostrar, e não narrar, incitando a curiosidade visual.

Para meu filme, defini dois parâmetros criativo-conceituais fundantes, em termos de uma metodologia poética para a estruturação das imagens, que são próprios do dispositivo mutoscópio, tanto na forma do carretel como no formato da exibição em tela: o loop e o flicker. Busquei, assim, contemplar a natureza dupla do artefato, preservando a investigação da descoberta no processo: a configuração singular e o mecanismo de exibição, o suporte e o meio, o filme e a projeção.

O cinema já começou em loop. Os filmes de Edison eram dispostos no kinetoscópio com as pontas de início e fim enlaçadas: oferecia um espetáculo aparentemente ininterrupto ao espectador que espiava pelo visor. Antes disso, os discos de praxinoscópio usados por Muybridge e Marey para reconstituir o movimento de seus filmes inaugurais também tinham no anel completo da curta circularidade contínua e fechada sua confi- 

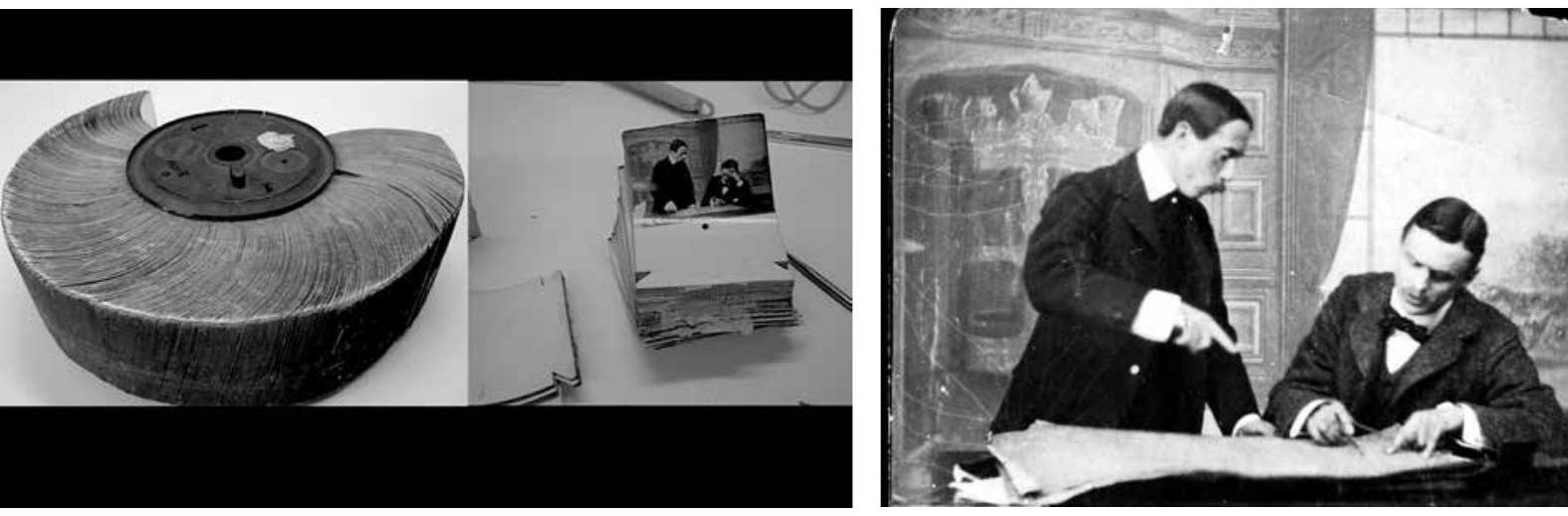

guração básica, por conta do número restrito de imagens aptas a serem impressas na extensão da emulsão do suporte.

Santos Dumont pré-cineasta? (2007-2010) é um ensaio documental e poético que se originou da tese de doutorado. A base da tese foi a descoberta e a restauração de um raro e extraordinário artefato protocinematográfico. Encontrei no acervo do Museu Paulista da USP, na coleção Santos Dumont, um carretel com 1.339 cartões fotográficos (658 cartões com imagem e 681 cartões brancos ou pretos), sem identificação de título, autoria, data, local e processo de produção7 ${ }^{7}$

Descobri que era um carretel de mutoscópio, dispositivo inventado entre 1894 e 1895 . No processo, as fotografias eram reproduzidas de fotogramas de um filme $68 \mathrm{~mm}$. O filme achado foi rodado pela filial britânica da American Mutoscope \& Biograph Co., importante companhia produtora das origens do cinema. Entre 22 e 28 de novembro de 1901, Santos Dumont esteve em Londres, homenageado pelo Aeroclube do Reino Unido, em função de sua conquista do Prêmio Deutsch em outubro (quando circundou a Torre Eiffel). Foi ciceroneado pelo aeronauta Charles Stewart Rolls, futuro fundador da Rolls-Royce.

O filme Santos Dumont explicando seu balão dirigível ao Hon. C. S. Rolls teve sua primeira exibição, com o projetor biógrafo, em 3 de dezembro de 1901, em sessão noturna do programa de variedades da Mutoscope \& Biograph no Palace Theatre, em Londres. Restaurei, digitalmente, o filme original de 1901 a partir dos cartões fotográficos, fotograma a fotograma, reordenando as imagens em sequência (o carretel estava partido) e acertando sua posição no quadro, de modo a produzir um movimento contínuo, restituindo sua original condição-cinema e permitindo minha reapropriação, com Santoscópio = Dumontagem .
Figura 4 carretel de mutoscópio: fotogramas do filme "Santos Dumont: pré-cineasta?" (Carlos Adriano)

Figura 5

fotograma do filme

"Santoscópio = Dumontagem"

(Carlos Adriano) 
Em Santos Dumont pré-cineasta? ? $^{8}$ faço o inventor brasileiro interagircompioneirosdocinemacomoMarey, Muybridge, Edson e Méliès, e com um curador de arquivos (Bernardo Vorobow). Cinema e aviação entram em graciosa rota de colisão, numa época de experiências intertextuais. A articulação desses signos em rotação encontra território fértil no arquivo do cinema.

Naquele mesmo ensaio sobre a meta-história, Frampton procedeu à conceituação-chave de "um cinema infinito", que projeta sua materialidade para além do sistema, e, em minha visão-intervenção, acomodaria o ideal de um arquivo infinito: "Antes da invenção da fotografia estática, os fotogramas do cinema infinito estavam vazios, uma ponta em branco, então umas poucas imagens começaram a aparecer sobre uma fita de filme sem fim. Desde o nascimento do cinema fotográfico, todos os fotogramas são preenchidos com imagens. Não há nada na lógica estrutural da tira de filme de cinema que impeça seqüestrar-se uma única imagem qualquer. Uma fotografia estática é simplesmente um fotograma isolado e retirado do cinema infinito." (FRAMPTON, 2009, p. 134).

Reciclando os primórdios do cinema em base digital (montagem e edição digitais de materiais filmados fotoquimicamecanicamente), do found footage ao database, pode-se configurar uma hipótese paratática: "o cineasta do banco de dados" (MANOVICH, 2001, p. 239). Correlata, deslinda-se a substituição de qualquer coleção de informações culturais (museu, biblioteca) pela base de dados do computador (MANOVICH, 2001, p. 217). Se Mallarmé achava que o mundo existia para acabar em livro, o mundo acabou mesmo em youtube, como o poeta Augusto escreveu em tvgrama 4 erratum (CAMPOS, 2015, p. 36-37).

A ruína é a evidência dos restos do tempo. $\mathrm{O}$ cinema de reapropriação re(in)staura a experiência das ruínas. Achar a imagem filmada é reprocessar o tempo reencontrado. Pensar o tempo como montagem de elementos heterogêneos: Justa posição poética. Aproximação de realidades distantes. Daí a graça e o assombro do encontro, do material encontrado. Como síntese apropriada e poética para uma prática de cinema, cito uma feliz formulação (MOORE, 2006, p. 67), em análise do filme (nostalgia) de Frampton, produzido no mesmo ano do ensaio sobre a meta-história, formulação que funciona também como justificativa para a alegoria da meta-história: "criar ruínas é o trabalho da sobrevivência”.

Uma das inspirações para meu penúltimo filme ${ }^{9}$, Sem título \# 1: Dance of Leitfossil (2013-2014), foi o trabalho de Aby Warburg (1866-1929), que tomava a história da arte como sobrevivência de formas (no caso, da Antiguidade no Renascimento). 


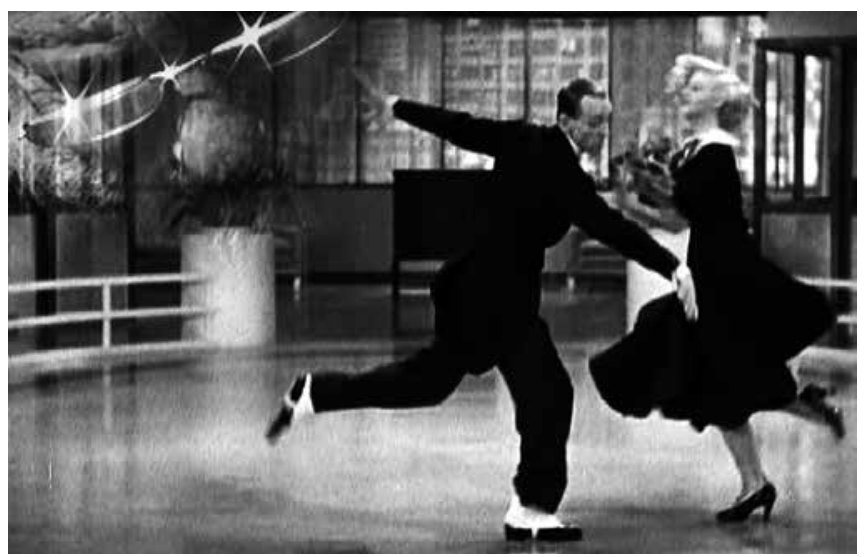

Warburg tem dois conceitos chave: "imagem sobrevivente" - a permanência de motivos antigos na arte de tempos posteriores (DIDI-HUBERMAN, 2013, p. 43), "fórmula de pathos" - "expressões visíveis de estados psíquicos que as imagens teriam fossilizado" (Gertrud Bing apud DIDI-HUBERMAN, 2013a, p. 23).

Na formulação do leitfossil - "a sobrevivência como memória psíquica passível de corporalização" (DIDI-HUBERMAN, 2013, p. 294) - e da imagem sobrevivente, AW trabalha os tempos enterrados, o fóssil como a "vida adormecida em sua forma" (DIDI-HUBERMAN, 2013, p. 293), o que provém de Bachelard: "Toda forma guarda uma vida. O fóssil [já] não é mais simplesmente um ser que viveu, [mas] é um ser que vive ainda, adormecido na sua forma." (BACHELARD, 1988, p. 183).

Em meu gabinete de curiosidades, não existe arquivo morto; só arquivos vivos, adormecidos em suas formas. No "leitfossil", dá-se "a sobrevivência como memória psíquica passível de "corporalização' ou de 'cristalização"' (DIDI-HUBERMAN, 2013, p. 294). Daí é um passo, ou um pas de deux, na dança de apropriação e incorporação. Como rima ao ritmo da dança do leitfossil, trago à lembrança: Warburg "fal[ava] da constante 'sinfonia de adeuses' que é a própria vida” (DIDI-HUBERMAN, 2013, p. 429).

Warburg fala em "apropriação por incorporação" (MICHAUD, 2013, p. 269), a propósito das reflexões sobre o pensamento mítico e a capacidade do homem em manipular coisas ("estabelecer ligações e separações"), porque, além da antiguidade grega, sua pesquisa voltou-se para os índios pueblos da América. $\mathrm{O}$ que me remete à bricolagem tal como sugerida por Levi Strauss sobre o pensamento selvagem. Nessas operações de AW há um gesto de escutar, auscultar as imagens: “(...)'resgatar o timbre das vozes inaudíveis' emitidas a partir das imagens" (DIDI-
Figura 6

Bernardo Vorobow, fotograma do filme "Sem Título \# 1: Dance of Leitfossil" (Carlos Adriano) 
-HUBERMAN, 2013, p. 35). São gestos que guardam várias analogias com o filme de reapropriação.

Como no inquietante [unheimliche] freudiano que surge o 'antigo familiar de outrora', a operação de "persistência do que resta, ainda que sepultado, por petrificação; persistência do que retorna, ainda que esquecido, por sopros de vento ou por movimentos-fantasma" (DIDI-HUBERMAN, 2013, p. 299) parece apropriada para o cinema de reapropriação. Para Warburg, a "imagem sofre de reminiscências" (DIDI-HUBERMAN, 2013, p. 273) e a memória inconsciente apreende-se como "nó de anacronismos" (DIDI-HUBERMAN, 2013, p. 27).

Arquivista convulso e compulsivo, Warburg trabalhou a organização do saber como arquivo. As imagens coligidas e montadas por ele no atlas Mnemosyne (em que ele justapôs reproduções de obras de arte de diversas épocas) seriam engramas - "imagem-lembrança" (DIDI-HUBERMAN, 2013, p. 206) - e (por consequência na analogia com a montagem) fotogramas (MICHAUD, 2013, p. 296) ${ }^{10}$.

Com seu atlas de imagens Mnemosyne Warburg instituiria "uma verdadeira metodologia de montagem do 'filme' na história da arte" (MICHAUD, 2013, p. 9), que conversaria à distância com a montagem de atrações representada tanto no cinema das origens como no filme eisensteiniano. O próprio Warburg chamou seu procedimento operacional de "iconologia dos intervalos" (MICHAUD, 2013, p. 240), o que para mim ecoaria na teoria de montagem de Dziga Vertov.

Pensando sobre Mnemosyne, "meses antes de morrer", Warburg afirmava "que a história das imagens deve ser compreendida como uma 'história de fantasmas para gente grande"' (DIDI-HUBERMAN, 2013, p. 426). Espectros e remanescências da imagem sobrevivente poderia ser um mote para os filmes de found footage.

Uma invenção extemporânea (talvez menos inapropriado que dizer "anacrônica") é justo a do "monólogo com" (o fantasma). Aludo ao expediente do Monólogo com Freud de Yerushal$\mathrm{mi}^{\mathrm{i}}$, final do livro que tanto encantou Derrida em Mal de arquivo, mas que caberia tão bem na compilação Mortes imaginárias de Schneider e no filme found footage. Eis a reprodução do monólogo de Yerushalmi com Freud: "Quando sua filha [Anna] fez chegar esta mensagem [sobre a acusação de que a psicanálise seria uma 'ciência judia'] ao Congresso de Jerusalém, era em seu nome que ela se exprimia? / Eu lhe peço, prezado professor, diga-me, 
prometo guardar o segredo., e conclui Derrida: "Estas são as últimas palavras do livro. Tudo parece selado por esta última assinatura em forma de promessa." (DERRIDA, 2001, p. 6o).

Maravilhado pelo que chamo dispositivo Yerushalmi, Derrida aposta na promessa de um método de imagem (DERRIDA, 2001, p. 54):

(...) se o scholar clássico não acreditava em fantasmas e na verdade não sabia como falar a eles, proibindo-se mesmo de fazê -lo, poderia bem ser que Marcelo [abertura de Hamlet] tenha antecipado a chegada de um scholar do futuro, de um scholar que no futuro, e para pensar o futuro, ousaria falar com o fantasma. De um scholar que ousaria confessar que ele sabe falar com fantasmas, pretendendo mesmo que isso não contradiga nem limite sua scholarship, mas que, ao contrário, a tenha condicionado à custa de alguma complicação ainda impensada que viesse dar razão ao outro, isto é, ao fantasma.

O dispositivo Yerushalmi parece apropriado para a reapropriação de arquivo:

(...) esta ficção tem uma outra originalidade que põe a ficcionalidade do 'monólogo' como que em abismamento [en abyme]: a apóstrofe é dirigida a um morto, ao objeto do historiador transformado em sujeito espectral, destinatário ou interlocutor virtual de um tipo de carta aberta. Outro efeito de arquivo. Em sua própria ficção, esta apóstrofe vem de fato enriquecer o corpus do qual ela pretende tratar, mas que ela amplia e do qual passa doravante a fazer parte" (DERRIDA, 2001, p. 55).

Não seria despropósito fazer o dispositivo Frampton (o do meta-historiador poético e artista) atuar aqui:

Como ousaria dizer-se historiador alguém que promete guardar segredo a um fantasma? (...) Yerushalmi escreve: '(...) $\mathrm{O}$ futuro, apesar das aparências, está sempre em aberto. A tarefa do historiador, felizmente, consiste em tentar compreender o passado. É hora do historiador se retirar e deixar falar as imagens (DERRIDA, 2001, p. 90).

Por que insistir aqui na espectralidade? Por que Yerushalmi ousou dirigir a palavra ao fantasma de Freud? Por que tece a 
audácia de lhe pedir uma resposta confidencial cujo arquivo ele não desvelará nunca? Sem dúvida, mas principalmente, porque a estrutura do arquivo é espectral (DERRIDA, 2001, p. 110).

Gostaria de evocar aqui, ou até mesmo invocar (quase como uma oração ateia), uma alegoria usada por Hannah Arendt (em 1968), a propósito de Walter Benjamin e por Didi-Huberman, a propósito de Aby Warburg. É a alegoria do pescador de pérolas que me parece apropriada às operações do cinema de reapropriação de arquivo. A essa alegoria, eu adjunto outra metáfora (sobre a vontade de comunicabilidade e o gesto que é do lance da arte), que é aquela da garrafa lançada ao mar. Mais do que pesquisador estilo detetive ou caçador de cabeças, Warburg foi "um pesquisador do tipo pescador de pérolas” (DIDI-HUBERMAN, 2013, p. 424).

Após o mergulho que lhe faz encontrar uma pérola, o pescador (satisfeito e iludido com o triunfo de seu troféu) fixa-a numa ficha catalográfica supostamente definitiva e guarda-a em vitrine, sem suspeitar que "para além do enigma, há um mistério de natureza totalmente diversa" (DIDI-HUBERMAN, 2013, p. 424). Até que ele repara, por acaso, e muito tempo depois, que a pérola era o olho de seu pai morto.

A alegoria seria "conforme a inesquecível profecia cantada por Ariel, em A tempestade (ato 1, cena 2), de Shakespeare: Eis a tradução de Carlos Alberto Nunes: "Teu pai está a cinco braças. / Dos ossos nasceu coral, / dos olhos, pérolas baças. / Tudo nele é perenal; / mas em algo peregrino / transforma-o o mar de contínuo." (DIDI-HUBERMAN, 2013, p. 424) ${ }^{12}$.

Obcecado, o pescador é impelido a um novo mergulho:

compreende que os tesouros do mar proliferam, existem em número infinito. Não só seu pai afogado deixou-lhe outras maravilhas além da pérola singular do começo, tais como o coral de seus ossos e inúmeros outros detalhes, transformados em 'tesouros insólitos', como há também, misturados ou dispersos, todos os corais e todas as pérolas de todas as gerações de ancestrais próximos ou distantes. Inúmeros pais jazem em inúmeros tesouros no fundo do mar. Coberta dealgas e impurezas, já se vão séculos que essa herança espera para ser reconhecida, colhida, repensada (DIDIHUBERMAN, 2013, p. 425).

A reapropriação de um tempo e um tesouro perdidos ecoam a caverna do cinema infinito de Frampton que projeta e protege a colheita dos materiais de arquivo. 
Noutra fase do mergulho (nas águas da memória e da percepção), o pescador compreende

que aquilo em que ele mergulha não é o sentido, mas o tempo. Todos os seres dos tempos passados naufragaram. Tudo se corrompeu, com certeza, mas tudo ainda está lá, transformado em memória, ou seja, em algo que já não tem a mesma matéria nem a mesma significação (...) (DIDI-HUBERMAN, 2013, p. 425).

Insígnio insight, arregimenta a convocação sedutora, intimação coercitiva e cognitiva:

No momento em que compreende isso, o pescador de pérolas sente um desejo imperioso: permanecer lá para sempre, fazer do meio orgânico em que ele nada - não do sentido dos próprios tesouros, mas da Leben dos fluxos que os possibilitaram - o objeto de sua busca. Ele bem sabe da loucura trazida por esse desejo: para conhecer completamente esse meio vital, esse meio de sobrevivência, seria preciso viver nele, afogar-se, perder a vida (DIDI-HUBERMAN, 2013, p. 425).

O autor das passagens promove o insígnio insight do desígnio:

Não se deve dizer que o passado esclarece o presente ou que o presente esclarece o passado. Uma imagem, ao contrário, é aquilo em que o Outrora encontra o Agora num relâmpago, para formar uma constelação. Em outras palavras, a imagem é a dialética em suspensão (BENJAMIN, 2006, p. 504).

Em sintonia (ora como ecos em reverberação, ora como de referências em rotação) à alegoria inaugural e fecunda de Benjamin (1984, p. 56) "As idéias se relacionam com as coisas como as constelações com as estrelas." - e à acepção dada por mim na metahistória, Werner Hofmann percebeu a organização dos elementos efetuada por Warburg em Mnemosyne como "constelações" (MICHAUD, 2013, p. 296).

Tratando de Benjamin, Arendt aborda a operação da memória e do arquivo:

(...) ele mergulha nas profundezas do passado, mas não para ressuscitá-lo tal como foi e contribuir para a renovação de épocas mortas. O que guia esse pensar é a convicção de que, se éverdade que o ser vivo sucumbe às devastações do tempo, o processo de decomposição é, ao mesmo tempo, processo de cristalização; a 
convicção de que, sob a proteção do mar - o próprio elemento anistórico no qual deve recair tudo aquilo que na história chegou e veio a ser -, nascem novas formas e configurações cristalizadas que, tornadas invulneráveis aos elementos, sobrevivem e aguardam apenas o pescador de pérolas que as levará à luz: como 'clarões de pensamento' ou também comofenômenos originários (citado por DIDI-HUBERMAN, 2013, p. 425-426).

No fim de uma conferência em 1912 em Roma, Warbur fez uma declaração tão enigmática quanto inspiradora (que eu até poderia adotar para esta conferência):

Caros colegas! Resolver um enigma em imagens - sobretudo quando não podemos esclarecê-lo de maneira simples e constante, mas apenas fornecer dele uma espécie de projeção cinematográfica - não foi, evidentemente, o objetivo de minha exposição (MICHAUD, 2013, p. 39).

Mas não vou terminar assim. Talvez eu recaia aqui em inconfidências, que de resto não o são porque estão escancaradas na tela quando se projetam meus três ${ }^{13}$ últimos filmes lançados (Santos Dumont pré-cineasta?, Sem título \# 1 : Dance of Leitfossil, Sem título \# 2: la mer larme), mas queria,se não tanto explicar ou explicitar, confessar meu encanto por estar falando disso num simpósio justamente sobre arquivos, memórias e afetos.

Nunca planejei, como plano piloto predeterminado, operar com found footage. Foi só após a morte de uma pessoa, é que percebi (ao menos racionalmente) por que me dediquei à reapropriação de arquivo com o leitmotiv singular dos fragmentos perdidos, esquecidos e desconhecidos do cinema brasileiro. E o fiz (por isso que no começo do texto falei em 'forma programática embora involuntária') justamente por causa de um genial programador de arquivos, museus e cinematecas.

Em 45 anos, Bernardo Vorobow (a.k.a. "o poeta da programação" e "o sr. Cinemateca”, Carlos Reichenbach dixit) foi diretor e programador da Sociedade Amigos da Cinemateca (quando esta funcionou no subsolo do Belas Artes, em sua época mais heróica, 1970-1975); coordenador de cinema do Museu de Arte Contemporânea da Universidade de São Paulo (1972-1976); criador, diretor e programador do departamento de cinema do Museu da Imagem e do Som de São Paulo (1975-1985); criador e diretor do departamento de difusão da Cinemateca Brasileira(1982-1999), e ali programador até 2009. 
Formou diversas gerações de cineastas e cinéfilos. Apresentou ao público brasileiro autores e filmografias, dos clássicos aos desconhecidos. Devotava um amor imenso ao cinema. Como programador, era imensa e intensa sua generosidade em compartilhar $^{14}$. Como um cineasta de reapropriação que trabalha com a montagem de materiais de arquivo num filme, um programador de cinemateca trabalha com a montagem de histórias do cinema ao compor programa(çõe)s de filmes (na tradição fundada por Jacques Ledoux e Henri Langlois). Só após sua morte é que pude explicitamente perceber que o Bernardo foi decisivo para que eu viesse a me dedicar aos filmes de reapropriação de aquivo.

Bernardo foi mais do que o coroteirista e o coprodutor de meus 11 filmes feitos até então. Farol e âncora, ele foi de certa forma o roteirista, o produtor e o programador de minha vida. Dance of Leitfossil' ${ }^{5}$ é o primeiro filme que concebo e realizo sem esta pessoa com quem tive o prazer e o privilégio de conviver por 27 anos (em 42 anos de vida, minha idade à data da perda irreparável). Após sua morte, pensei que não seria mais possível fazer filmes; na verdade, para mim não faria mais sentido, porque perdi o espectador e o interlocutor primordial e privilegiado, para quem eu sempre fazia (faço e farei) meus filmes. Mas tive um insight ao conceber a série dos Sem título, "apontamentos para uma AutoCineBiografia (em Regresso)", e passei a fazer cinepoemas de amor (ao cinema,à vida ...) - com todas as penas que isso implica (e a saudade não é a menor delas).

Sempre lembro de um fragmento do Canto 81 de Ezra Pound (tradução: Augusto e Haroldo de Campos e Décio Pignatari) (CAMPOS, 1983, p. 202):

O que amas de verdade permanece, o resto é escória

O que amas de verdade não te será arrancado

$\mathrm{O}$ que amas de verdade é tua herança verdadeira.

Assim como o arqueólogo escava a terra para encontrar fragmentos de fósseis que possam ser recompostos num corpo orgânico e coerente, reparo que a palavra memória contém, como anagrama encapsulado, as letras soltas que, recompostas e então dotadas de sentido, geram a palavra amor. Caberia uma inversão à saudação que consta do pórtico de alguns cemitérios. Em vez do "Nós que aqui estamos por vós esperamos", eu proporia "Nós que aqui ficamos por vós ..., deixando reticenciais a desinência ea resistência. O vão império (se o há) de nossas conquistas são as ruínas de nossas memórias. 
Sempre me lembro de uma formulação lapidar de Nietzsche, que transcende o limite fisiológico e o hermenêutico: "nós precisamos da arte para não morrer de verdade". Memória é afeto. A cada segundo de cada minuto de cada hora de cada dia de cada semana de cada mês de cada ano que ainda nos resta, somos programados para manter não apenas a memória de um amor, mas o próprio amor e a gratidão por tê-lo merecido. E assim todos que sofremos alguma espécie de perda tentamos seguir na vida, com a vida. Além de respirar, tento continuar fazendo filmes, agora com uma surplus: que honrem um tesouro de ouro. Tento.

Pois, como escreveu Proust, "os verdadeiros paraísos são os paraísos perdidos".

Com a metade que me falta.

NOTAS

1. Ver o Dossiê Found Footage por mim organizado (informação em Referências).

2. Argumento desenvolvido em minha tese de doutorado.

3. Em meu último filme (Sem título \# 2: la mer larme) faço as ondas de Marey e de Cunha Salles dialogarem.

4. Frampton alude aqui ao ano de produção do filme Meshes of the afternoon, de Maya Deren e Alexander Hammid, considerado marco da vanguarda americana.

5. Mesmo conhecendo as normas da ABNT, adoto o critério (como fiz na tese de doutorado) de manter as citações diretas mais longas no corpo do texto (e não com o destaque de recuo de página, corpo menor e espaço simples entre linhas). Meu critério busca criar uma rima visual com o efeito de colagem, tônica temática e formal do artigo (e da tese), e acentuar a mistura. A norma me parece separar as citações do texto, quando a intenção, aqui coerente, seria de integrar, interagir, mixar, samplear: dados de informação como found footage, como na montagem e edição de um filme de reapropriação de arquivo.

6. Todos filmes coproduzidos por Bernardo Vorobow.

7. O processo de descoberta e restauração da peça encontra-se descrito em minha tese de doutorado.

8. Ler crítica ao filme escrita por Eduardo Valente: Filme de amor. Revista Cinética, set. 2010. Disponível em: <http://www.revistacinetica.com.br/santosdumontpre.htm>. Acesso em: 11 nov. 2015.

9. À altura da revisão deste artigo, finalizo Sem título \# 3 : E para que poetas em tempo de pobreza?, com estreia prevista para o primeiro semestre de 2016.

10. Richard Semon (A memória como princípio constitutivo do devir orgâni$c 0,1904)$ definiu a marca na memória cravada por todo acontecimento que afeta a matéria orgânica ou o ser vivo como sendo um "engrama”.

11. O livro de Yosef Hayim Yerushalmi é Freud's Moses, Judaism terminable and interminable (Yale University Press, 1991).

12. No original: Full fathom five thy father lies; / Of his bones are coral made; / Those are pearls that were his eyes: / Nothing of him that doth fade 
/ But doth suffer a sea-change / Into something rich and strange.

13. Ver nota 8.

14. Para saber mais sobre ele, consultar o Dossiê Bernardo Vorobow na revista Trópico, com textos de Carlos Reichenbach, Walter Salles e Carlos Adriano. Disponível em: http://p.php.uol.com.br/tropico/html/textos/3119,1.shl http://p.php.uol.com.br/tropico/html/textos/3121,1.shl, http://p.php.uol. com.br/tropico/html/textos/3120,1.shl. Acesso em:11 nov. 2015.

15. A propósito deste filme, ver o artigo de Scott MacDonald A sudden passion: Carlos Adriano's Sem título \# 1 : Dance of Leitfossil publicado em Film Quarterly, New York, fall 2015, volume 69, number 1, p. 45-51.

\section{Referências}

ADRIANO, Carlos (Ed.). Dossiê Found Footage (I). São Paulo, Revista Laika, set. 2015. Disponível em: < http://www.revistalaika.org/no-o>. Acesso em: 11 nov. 2015.

BACHELARD, Gaston. A poética do espaço. Os pensadores. São Paulo, Nova Cultural, 1988.

BENJAMIN, Walter. Passagens. Belo Horizonte / São Paulo: Editora UFMG / Imprensa Oficial do Estado de São Paulo, 2006. . Origens do drama barroco alemão. São Paulo: Brasiliense, 1984.

CAMPOS, Augusto de. Ezra Pound: poesia. São Paulo / Brasília: Hucitec / Universidade de Brasília, 1983. . Outro. São Paulo: Perspectiva, 2015.

CARROLL, Noël. A brief comment on Frampton's notion of metahistory. Millennium Film Journal, Nova York, n. 16/17/18, p. 200-205, 1986-1987.

DERRIDA, Jacques. Mal de arquivo: uma impressão freudiana. Rio de Janeiro: Relume Dumará, 2001.

DIDI-HUBERMAN, Georges. A imagem sobrevivente: história da arte e tempo dos fantasmas segundo Aby Warburg. Rio de Janeiro: Contraponto, 2013.

Prefácio. In: Michaud, Philippe-Alain. Aby Warburg e a imagem em movimento. Rio de Janeiro: Contraponto, $2013 a$.

ELSAESSER, Thomas (Org.). Early cinema: space frame narrative. London: British Film Institute, 1990.

FRAMPTON, Hollis. On the camera arts and consecutive matters. (Org).: Jenkins, Bruce. Cambridge, Massachusetts / London: The Massachusetts Institute of Technology Press, 2009.

GUNNING, Tom. The cinema of attractions: early film, its spectator and the avant-garde. In Elsaesser, Thomas (Org.). Early cinema: space frame narrative. London: British Film Institute, p. 56-62, 1990.

. Uma estética do espanto: o cinema das origens e o especta- 
dor (in)crédulo. Imagens, São Paulo, n. 5, p. 52-61, ago./dez. 1995. MANOVICH, Lev. The language of new media. Cambridge, Massachusetts: The Massachusetts Institute of Technology Press, 2001.

MICHAUD, Philippe-Alain. Aby Warburg e a imagem em movimento. Rio de Janeiro: Contraponto, $2013 a$.

MOORE, Rachel. Hollis Frampton: (nostalgia). London: Afterall Books, 2006.

ROSA, Carlos Adriano Jeronimo de. O mutoscópio explica a invenção do pensamento de Santos Dumont: cinema experimental de reapropriação de arquivo em forma digital. 2008. Tese (Doutorado em Ciências da Comunicação, área de concentração Estudo dos Meios e da Produção Mediática) - Universidade de São Paulo (Escola de Comunicações e Artes), 2008.

. Um cinema paramétrico-estrutural: existência e incidência no cinema brasileiro. 2000. 112 f. Dissertação (Mestrado em Ciências da Comunicação) -Escola de Comunicações e Artes, Universidade de São Paulo, 2000.

SCHNEIDER, Michel. Mortes imaginárias. São Paulo: Girafa, 2005.

SITNEY, P. Adams. Visionary film. New York: Oxford University, 1974.

STRAUVEN, Wanda. The cinema of attractions reloaded. Amsterdam: Amsterdam University Press, 2006.

ZRYD, Michael. História e Ambivalência no Magellan de Hollis Frampton. In: ADRIANO, Carlos (Ed.). Dossiê Found Footage ( I ). São Paulo, Revista Laika, set. 2015. Disponível em: <http://www.revistalaika.org/no-o>. Acesso em: 11 nov. 2015.

Recebido em: 10/o6/15

Aceito em: 01/o8/15

\section{CARLOS ADRIANO}

adriano.carlos.ca@gmail.com

Cineasta, doutor em cinema (USP), pós-doutor em artes (PUC-SP) e pós-doutorando em cinema (USP). Recebeu as bolsas de Doutorado e de Pós-Doutorado Fapesp e de Pós-Doutorado Capes. Em 26 anos realizou 13 filmes, como: Remanescências; $A$ voz e o vazio: a vez de Vassourinha; Santoscópio = Dumontagem; Santos Dumont pré-cineasta?; Sem Título \# 1: Dance of Leitfossil e Sem Título \# 2: la mer larme. 